\title{
El arte y lo tecnológico: una reflexión desde la comunicación/cultura
}

\section{The art and the technological: a reflection from the communication/culture}

ENSAYO

\author{
Lía Gómez y Bianca Racioppe \\ Universidad Nacional de La Plata, Argentina \\ lialaig@gmail.com; bianca_racioppe@yahoo.com.ar
}

Recibido: Julio del 2016

Aceptado: septiembre del 2016

\begin{abstract}
Resumen
El presente artículo reflexiona en torno al vínculo entre el arte y la tecnología desde una mirada comunicacional. En un primer momento, se problematiza acerca de la relación de las tecnologías con las prácticas artísticas entendiéndola como parte de un proceso histórico anterior a la informática e, incluso, a la fotografía, generalmente pensada como uno de los primeros momentos de tecnologización de lo artístico en el campo del arte visual.

En un segundo momento, se retoman y analizan, desde este marco conceptual, dos experiencias artísticas que se construyen a partir del vínculo con softwares y hardwares. Se problematiza la relación con los públicos y la concepción del arte como un juego (Gadamer; 1991). La reflexión final aporta la dimensión política y complejiza la mirada acerca de la relación arte-tecnología.
\end{abstract}

Palabras claves: Arte; comunicación; tecnologías.

\section{Abstract}

This article reflects on the link between art and technology from a communicational perspective. At first, it problematizes about the relationship of technology with artistic practices understood as part of a historical process which is previous than computer and even photography. We refer to the photography because it is generally considered the first articulation between visual art and technology.

In a second stage, we take two artistic experiences that are constructed from the link between software and hardware. The article problematizes the relationship with the public and the conception of art as a game (Gadamer; 1991). The final reflection brings the political dimension to the complex relationship between art and technology.

Keywords: Art; communication; technology. 


\section{Comunicación mediática - arte mediático. Primeras reflexiones}

El enfoque que desarrollamos en este artículo se sustenta en la idea de que la relación del hombre con las tecnologías es parte del proceso de la historia de la humanidad; el hombre siempre ha sido creador de tecnologías que le han permitido modificar su entorno. Por lo tanto, cualquier práctica social está atravesada por el desarrollo y uso de tecnologías, y entre ellas se incluye, claramente, la práctica artística. Siguiendo a Arlindo Machado (2004, p. 85) se sostiene que "El arte siempre fue producido con los medios de su tiempo" lo que implica sostener que lo tecnológico y lo artístico siempre han estado articulados. Sin embargo, antes de desarrollar este planteo, se realiza un análisis de los mitos que sostienen el vínculo de la comunicación y del arte con las tecnologías.

La problematización de las tecnologías desde el campo de la comunicación/cultura ha permitido complejizar el análisis y ponerlo en diálogo con las tramas sociales y políticas; dejar de pensar en aparatos o instrumentos para comprender que sus lógicas de diseño y de uso se inscriben en ideologías y posiciones frente al mundo. Desde este anclaje epistemológico, se entiende -siguiendo a Williams (1992)- que la comunicación siempre ha estado vinculada a lo tecnológico porque la escritura es ya una tecnología que nos ha posibilitado no sólo describir, sino principalmente construir el mundo.

Actualmente, en muchos de los estudios de comunicación, cuando se piensa a las tecnologías se comparan los cambios que introdujo la imprenta con los que ha incorporado Internet. Pese a que la comparación peca de desconocer las diferencias entre los contextos de desarrollo de estos medios, permite ver que a la relación comunicacióntecnología se le reconocen más de cinco siglos de existencia ya que el desarrollo de la imprenta aparece como un hito en la comunicación mediática (Thompson, 1998). Nadie dudaría de eso. Sin embargo, al hablar de la relación entre el arte y la tecnología generalmente se alude a la fotografía como el primer desarrollo técnico que en el siglo XIX puso en jaque a la producción artística visual. Así lo explica Walter Benjamin en su texto "Pequeña historia de la fotografía" en el que da cuenta de algunos de los debates que surgieron en torno a la posibilidad de que la fotografía fuera entendida como un arte:

Sobrias en cambio, incluso pesimistas, son las palabras con las que dos años más tarde anuncia Baudelaire a sus lectores la nueva técnica en el Salón de 1859. Igual que las que acabamos de citar, tampoco éstas pueden leerse sin un ligero desplazamiento de acentos. Pero en tanto que son la contrapartida de aquéllas, guardan todo su sentido como la más afilada defensa contra todas las usurpaciones de la fotografía artística. «En estos días deplorables se ha producido una nueva 
industria que ha contribuido no poco a confirmar la estupidez por su fe... en que el arte es y no puede ser más que la reproducción exacta de la naturaleza... Un dios vengativo ha dado escucha a los votos de esta multitud. Daguerre fue su Mesías... Si se permite que la fotografía supla al arte en algunas de sus funciones, pronto le habrá suplantado o corrompido por completo gracias a la alianza natural que encontrará en la estupidez de la multitud. Es pues preciso que vuelva a su verdadero deber, que es el de servir como criada a las ciencias y a las artes.» (Benjamin, 1989, pp. 81 y 82)

En la narración de Benjamin aparecen tensiones y opiniones diversas que produjo el desarrollo de la fotografía y su incorporación al campo del arte. Así la relación artetecnología se asienta en un mito fundacional que se construye desde la disputa. Todo lo que la tecnología aporta a la comunicación permitiendo la producción en serie, la separación de los lugares de producción de los de recepción, la desvinculación del transporte físico (Thompson, 1998) es visto como potencialidad para la construcción de las industrias mediáticas. En cambio, esas mismas características son leídas como peligrosas para la Institución arte: la pérdida del aura entendida como problema y no como posibilidad, lo único y lo auténtico avasallados por la reproductibilidad mecánica. Las miradas de los teóricos de Frankfurt, Adorno y Horkheimer, que ven en la tecnicidad de la Industria Cultural la clausura de lo artístico.

Sin imprenta -en tanto tecnología y en tanto organización productiva- no se podría haber pensado en los periódicos y las revistas, las tecnologías se entraman, así, en lo constitutivo de la comunicación mediada. Por otro lado, la historia hegemónica del arte, que se sustenta en una tradición pictórica, leyó a la tecnología en tanto amenaza -en los términos en que lo revela la cita que Benjamin hace de Baudelaire- del "arte verdadero", aquel arte separado de la artesanía y, por lo tanto, de la producción seriada. Esta tradición de pensamiento artístico, que los Estudios Visuales contemporáneos critican, tiene su origen cuando el artista se desvincula del taller de artesanos (Véanse Graw, 2013; Gimpel, 1979) y el arte empieza a pensarse como la más profunda expresión del sentir de un individuo artista, el contacto directo entre el creador y su obra. Una creación que de ningún modo podría estar mediada por la máquina, entendida como lo inhumano. Sin embargo, la fotografía y luego el cine consiguieron un espacio en las galerías, los museos, los concursos, en la Institución arte. Más allá de los reparos de Adorno y Horkheimer ([1947] 1998) la tecnología no obturó al arte crítico; por el contrario muchas de las expresiones más revolucionarias de los últimos tiempos han sido producidas a partir de un arte explícitamente vinculado a lo tecnológico.

Benjamin, quien a veces fue vinculado a la Escuela de Frankfurt, sostuvo un debate con Adorno y Horkheimer en relación a los modos de entender lo artístico. Benjamin se corrió de la mirada canónica de la obra como objeto único para ver la potencialidad de la reproducción mecánica. Incluso en su texto "La obra de arte en la época de su 
reproductibilidad técnica" que a veces fue leído como una crítica a lo tecnológico en pos de lo aurático, el autor puso en crisis la idea de autenticidad y unicidad:

Podríamos decir que el invento de la xilografía atacó en su raíz la cualidad de lo auténtico, antes desde luego de que hubiese desarrollado su último esplendor. La imagen de una virgen medieval no era auténtica en el tiempo en que fue hecha; lo fue siendo en el curso de los siglos siguientes, y más exuberantemente que nunca en el siglo pasado (Benjamin, [1936] 1989, p. 21)

Benjamin evidenció que el problema de lo original y lo auténtico era un problema moderno que se originó, tal como señalábamos antes, cuando se separó al artesano del artista. Esa construcción de una mirada de Bellas artes fue la que habilitó el desprecio hacia aquello que podía masificarse, en el sentido de ser producido industrialmente. Antes de avanzar y recuperar algunas experiencias contemporáneas, es importante retomar la idea sostenida al comienzo de este artículo: que el vínculo del arte visual con la tecnología no empieza con la fotografía -ni siquiera con la xilografía-, sino que es tan antiguo como la relación del hombre con el arte. Siguiendo a Arlindo Machado, podemos sostener:

El arte siempre fue producido con los medios de su tiempo. Bach compuso fugas para clave porque éste era el instrumento musical más avanzado de su época en términos de ingeniería y acústica.(...) Edgar Degas, que nace casi simultáneamente con la invención de la fotografía, utilizó extensivamente esa tecnología no sólo para estudiar el comportamiento de la luz, que él traducía en la técnica impresionista, sino también en sus esculturas, para congelar cuerpos en movimiento con la misma frescura con que lo hacía el rapidísimo obturador de la cámara. (...) ¿Por qué, entonces, el artista de nuestro tiempo rechazaría el video, la computadora, Internet, los programas de diseño, procesamiento y edición de imagen? (Machado, 2004, p. 85)

La afirmación de Machado nos permite comprender que la tecnología no es algo externo al arte, sino algo que siempre lo había atravesado constituyendo oportunidades para nuevas estéticas, nuevas narrativas. Si seguimos los planteos de Philippe Dubois, podemos sostener que ya en las pinturas rupestres se utilizaban tecnologías:

En cierto modo, resulta bastante evidente que toda imagen, hasta la más arcaica, requiere una tecnología, por lo menos de producción, a veces de recepción, puesto que presupone un acto de fabricación de artefactos que necesita tanto de útiles, reglas, condiciones de eficacia, cuanto de un saber. (...) De ese modo, se podrían ya leer como "productos tecnológicos", por ejemplo, las famosas y paleolíticas manos negativas (o "al patrón") de las grutas del Pech Merle (de -20.000 a- 60.000 años), las que, por elementales que sean, necesitaban ya un dispositivo técnico de base, hecho de un recipiente ahondado, de polvo pigmentado, del soplo del "escribiente", de un muro-pantalla, de una mano-modelo posada sobre la superficie y de un dinamismo particular que articulara todos esos elementos (la proyección). (Dubois, 2000, s/p) 
A partir de estos autores se argumenta que el vínculo arte-tecnología es intrínseco a la producción artística, que no pueden pensarse como separados, sino que deben ser comprendidos en sus diálogos.

En esta relación entre arte-tecnología es pertinente ubicar la perspectiva contextual e histórica que nuclea a cada uno de los objetos con el mundo. En este sentido, Héctor Cartier sostuvo que el arte es una "experiencia vital", que no puede ser aprisionada en conceptos discursivos que la expliquen, sino que debe invitar a la reflexión a partir de considerar las representaciones que en ella se exponen para la comprensión del sentido en el territorio de la cultura. La comunicación debe ubicar su diálogo con el campo artístico interpretando esa relación entre obra y mundo. (Cartier, inédito)

El arte en cuanto auténtica actividad creativa, es generado a partir de una emoción sentida en dimensión inteligible, que descubre el ser de las cosas más allá de lo que presenta, es decir que no explica ni describe, presenta existiendo y desde el mundo de las formas (Cartier, 1961, p. 4)

Con la transformación tecnológica los modos de habitar y percibir se transforman y, por ende, el universo artístico vive en un permanente desajuste entre la historia del arte y las innovaciones artísticas. Un desajuste que no es lineal sino convergente y que propone desde las primeras vanguardias hasta la actualidad reflexionar sobre las multiplicidades en el arte digital.

Desde la idea de una techné que implica un saber hacer humano ${ }^{1}$ y que, en cierta forma, Raymond Williams (1992) recupera al definir a las tecnologías, se piensa a las experiencias contemporáneas que hacen arte a partir de lo tecnológico.

Al respecto, analizar la técnica como forma cultural, y a la tecnología como uso social de la primera, nos permite tomar posición en torno al modo de abordaje sobre el problema de la técnica y el arte en la era tecnológica.

Dice Jesús Martín Barbero:

(...) lo que la revolución tecnológica de este fin de siglo introduce en nuestras sociedades no es tanto una cantidad inusitada de nuevas máquinas, sino un nuevo modo de relación entre los procesos simbólicos -que constituyen lo cultural- y las formas de producción y distribución de bienes y servicios: un nuevo modo de producir, inextricablemente asociado a un nuevo modo de comunicar, convierte al conocimiento en una fuerza productiva directa (2003, pp. 80-81)

Según indica indica Martín Barbero, el tiempo, el espacio y los modos de relacionarnos con la producción y recepción de obras artísticas, del mismo modo que los imaginarios a los que nos enfrentamos, constituyen una amalgama de sentidos a los que

1 La definición de techné, según el análisis que hace del concepto José Jiménez, designa "aquello distinto de la naturaleza (la physis), nombraba, entonces, lo producido por el hombre (pero no sólo en tanto objetos, artesanías, sino también en tanto habilidades, pensamientos). Dentro de la techné se incluye la techné mimetiké, la habilidad de producción de imágenes". (Jiménez; 2002: 55) 
debemos estar alertas para comprender el arte como expresión sociocultural política y tecnológica o, como "forma cultural" (Williams, 2011). El encuentro entre el arte y la tecnología marcó, desde los inicios, una evolución de doble sentido: técnico, ligado a las herramientas de uso; y simbólico, vinculado a las formas de expresión que permiten el desarrollo tecnológico.

\section{Arte, interacción y código abierto}

Se ha señalado que la fotografía influyó en la mirada de la pintura occidental y contribuyó a generar nuevos lenguajes más allá de la propia fotografía. Es decir cada medio, cada tecnología aporta a la construcción de las estéticas. En este sentido, las tecnologías digitales, los llamados nuevos medios o artemidia (Machado, 2004) reconfiguran el sentido de la exposición al proponer una interacción que se vale de softwares y hardwares para redefinir el espacio del museo y de la galería.

En referencia a ello José Luis Brea sostiene:

(...) la confluencia de las prácticas artísticas y las tecnologías electrónicas es extremadamente fértil. No solo porque las posibilidades de producción de formas visuales que proporcionan las tecnologías digitales de generación y tratamiento de la imagen (enriquecida por los desarrollos multimedia que acrecientan las posibilidades de su riqueza expresiva) son enormes, sino también porque sus potenciales de distribución al tejido social, superan por mucho, los otros canales más tradicionales (2007, p. 172)

Una de las principales características de las producciones artísticas realizadas a partir de tecnologías electrónicas es que proponen la interacción del público de una manera que va más allá de la contemplación, ligándose al sentido de lo artístico que sostenían las vanguardias y al concepto de arte que desarrollaron pensadores como Gadamer (1991)

Si bien la interactividad no inició con el arte electrónico (véanse los mitos a los que refiere Manovich, 2005), una de las principales características de estas producciones era que no se exponían sólo con la idea de ser contempladas sino que el sentido de la obra se ampliaba en la relación con ese público.

En este marco, la experiencia de Biopus -un proyecto creado por Emiliano Causa, Christian Silva, Tarcisso Pirotta y Julián Issach; actualmente formado por Emiliano Causa y Matías Romero Costas- tiene entre sus principales objetivos explorar las relaciones entre los públicos y la obra.

Podemos ubicar aquí dos variables a ser problematizadas: por un lado, la noción de "público de arte" y por el otro, la propuesta del "arte electrónico". En el primer caso, en toda exposición, sea en el espacio que sea, conviven dos tipos de públicos: el especialista, que por lo general recorre la muestra con una mirada formada, con ciertas nociones incluso de 
curaduría, y el transeúnte que observa desde múltiples lugares. Pero en ambos, la obra se ubica como cosa pública, como escena a ser compartida y (re)creada en la relación con el otro. Encontramos allí una práctica cargada de politicidad en cada uno de los momentos generados, desde la creación de la obra, la puesta en forma de la muestra y la vinculación con la visión del público que la habita en toda su dimensión posible.

Siguiendo a Lev Manovich (2005, p. 180), podemos señalar que "el arte electrónico se basó desde el comienzo en un nuevo principio, que es el de la modificación de una señal ya existente"; y que, principalmente, lo que nos permite es fijar a través del uso de la tecnología electrónica, objetos, sensaciones, texturas, imaginarios que involucran al público como elemento de significación.

Uno de los primeros trabajos de Biopus se llamó "Acecho, persecución y muerte" (2001) y consistía en un video en el que la imagen y el sonido electroacústico se complementaban para provocar la sensación de felinos cazando gacelas. El sonido generaba una sensación de inmersión en la obra que hacía imposible contemplarla desde la distancia solemne con la que uno se acerca a La Mona Lisa ubicada tras un vidrio en el Louvre. Así, el arte electrónico, basándose en la tradición de la performance, transforma no sólo la relación con los públicos, sino también con la curaduría, con la forma de poner en escena esa presentación.

En la muestra "Los mundos imaginarios" en el Museo de Arte Contemporáneo de Mar del Plata (MAR) se exhibió "Osedax", una instalación interactiva de Biopus de 2012 que simula el cuerpo de una ballena dentro del que se ven distintos animales. A medida que los públicos se trasladan alrededor de la ballena los colores van mutando y proyectándose en la sala en tinieblas. El arte como juego, jugar a ver las formas proyectadas en los cuerpos, jugar a cambiar los colores ante el simple desplazamiento. El cuerpo se convierte en elemento que transforma la obra y la hace única en cada uno que la atraviesa, se convierte en una mediación continua entre el momento creador y la exhibición. "Osedax" es, de este modo, una performance que -tal como los miembros de Biopus la definenbusca generar que el público construya una relación entre su cuerpo y la instalación, ya que la misma demanda una constante intervención para mantenerse viva.

(...) no está demás recordar que con el computador no estamos ante la tradicional relación de un cuerpo y una máquina, relación dedicada al ahorro de fuerza muscular, o de la repetición infinita de la misma tarea, sino ante una aleación de cerebro e información, incomprensible por fuerza de la invocación radical que introduce las nuevas figuras de razón que ha posibilitado la razón técnica (Martín Barbero, 2006, p. 20)

Lo lúdico, e incluso los juegos de la multiplicidad de lenguajes del arte, encuentran en el territorio del arte electrónico un universo a ser explorado que -tal como señala Martín Barbero (2006)- propone nuevas figuras de forma y de razón para el arte contemporáneo. El cuerpo como primer elemento comunicante del ser humano se encuentra aquí en una 
extensión posible como objeto artístico y desde allí, interviene en la puesta y en la producción de conocimiento.

En ese interactuar y jugar se da un proceso que pone en tensión la idea del creador y de la creación como un "estar en el origen" (Bourriaud, 2009). En ese diálogo evidente entre la tecnología y el arte, la producción artística recupera del desarrollo tecnológico, y especialmente del software, el trabajo procesual: la obra nunca está completa, nunca está acabada sino que se realiza en cada exhibición y en la articulación con los públicos. Además, hay en esta práctica artística una lógica vinculada al "Do it yourself" -hazlo por ti mismo- que también la relaciona a la escritura del código del software y a las comunidades de hackers. En esta lógica del "hazlo por ti mismo" es central la idea de la experiencia y del aprendizaje en el proceso del hacer. Así, el concepto de techné como aquello "producido por el hombre (pero no sólo en tanto objetos, artesanías, sino también en tanto habilidades, pensamientos)" (Jiménez, 2002, p. 55) cobra otras dimensiones.

Por otro lado, el arte electrónico se vincula a lo abierto no sólo por ser una obra en constante proceso, sino también porque los principales softwares que se usan para realizarlo son de código abierto. Esto se debe, según explica Emiliano Causa, ${ }^{2}$ a que el software libre, por sus lógicas de construcción colaborativa, tiene actualizaciones constantes y además, permite compartir y publicar los desarrollos -algo que impide el trabajo con software privativo. Por eso, los softwares más utilizados son Processing, Pure Data que son de código abierto y también hardwares abiertos como Arduino. ${ }^{3}$ De hecho en la página web de Biopus tienen una sección de tutoriales en los que se explican usos de diferentes softwares, de lenguajes de programación y se comparten desarrollos de las obras.

En este vínculo entre el software, el arte y la actitud de código abierto se puede mencionar también la experiencia de Moldeo que propone una "plataforma de código fuente abierto que posibilita la realización de entornos interactivos con elementos de video y animación -en dos y tres dimensiones- y con efectos digitales en tiempo real" como explican en su web. ${ }^{4}$ Este proyecto es impulsado por Fabricio Costa Alisedo, Javiera Sáez Mansilla y articula con la investigación sobre arte y cuerpo que lleva adelante Alejandra Ceriani. El programa puede descargarse libremente de la web, además se comparte la documentación y se invita a integrar la comunidad Moldeo, a "crear, clonar y compartir". A

$2 \quad$ Emiliano Causa en una entrevista realizada en el marco de la investigación para la tesis doctoral de Bianca Racioppe en la que se lo consultó por el uso de softwares libres en la Facultad de Bellas Artes de la UNLP. La entrevista fue realizada telefónicamente el 30-9-2014.

3 Processing: lenguaje de programación que sirve para el desarrollo de proyectos multimedia. https://processing.org/

Pure Data: lenguaje de programación para proyectos multimedia https://puredata.info/

Arduino es una compañía de hardware libre que desarrolla placas para proyectos interactivos. https://www.arduino.ccl

$4 \quad$ Sitio web de Moldeo http://www.moldeo.org/ 
su vez, se comparten en la web distintos proyectos de entornos interactivos realizados a partir de clonar y derivar patrones presentes en Moldeo.

El software y el programador interactúan en tiempo real con actores, bailarines generando una puesta en escena que es totalmente efímera porque se da en ese mismo momento. Una interacción entre el cuerpo y la tecnología, entre lenguajes artísticos que corresponden a los territorios analógicos (como el teatro y la danza) y lo digital.

De esta manera lo explica Alejandra Ceriani en la sinopsis de uno de los proyectos desarrollados con Moldeo:

El cuerpo es captado por una cámara, y este movimiento es traducido y reinterpretado en paradigmas visuales y sonoros que, a su vez, se combinan y realimentan con el material propiamente generado por el músico y diseñador del sonido y por el programador y diseñador de imagen. Se llega así a una trama de estado cinestésico, a un cruce de sentidos de múltiples lecturas, que transcurre por diferentes estados y participaciones de los artistas. (s/f)

Así como en "Osedax" de Biopus, en las performances que se realizan con Moldeo el cuerpo entra en diálogo con el software para producir la obra. También invita al juego, a lo lúdico de clonar el cuerpo en un avatar digital que se mueve por escenarios informáticamente construidos. Tanto Moldeo como Biopus son experiencias que dan cuenta de la interrelación entre el arte y la programación, entre los artistas y los programadores o los artistas/programadores. Experiencias que dan cuenta de cómo se están transformando los conceptos canónicos de obra, público y artistas atravesados por las tecnologías y por las lógicas de los desarrollos tecnológicos.

\section{Arte, tecnología, comunicación y política. Una reflexión final preliminar}

Pensar el arte desde la comunicación implica el desafío de corrernos de las miradas legitimistas que resaltan cierto tipo de producciones artísticas, para pensar desde las prácticas, desde los entramados de sentidos. En este enfoque de inscribir el arte en la cultura (Martín Barbero, 2005) -y no a la cultura en el arte- la mirada comunicacional se vuelve central para visibilizar las luchas y las tensiones en torno a lo que se entiende por práctica artística.

En la actualidad, el universo se ve ampliado por los desarrollos tecnológicos que permiten un mayor acceso a la producción, distribución y recepción de las obras, como así también a la constitución de nuevas formas y sensibilidades; podemos decir que el siglo XXI se presenta con la riqueza compleja de un caudal simbólico en donde las identidades del campo del arte se movilizan entre las relaciones hegemónicas que comprende el carácter de la comunicación en su conjunto.

De este modo, este nuevo siglo encuentra la relación constitutiva del arte y la política centrada ya no sólo en las relaciones hegemónicas de forma y contenido como centro del 
debate, sino también en algunas condiciones que amplían necesariamente el horizonte de conocimiento: la facilidad de transmisión de la imagen en la era de lo electrónico y digital, las formas narrativas propias de las Ilamadas nuevas tecnologías, la movilidad productiva de los artistas, la puesta en tensión de los elementos creativos, la reconfiguración de los espacios de exhibición, y la resignificación de múltiples públicos y del valor de lo público.

En esta dirección, los lenguajes, técnicas y procedimientos que estas relaciones invitan a comprender construyen datos de los sentidos para transformarlos en objetos de cultura, política y civilización. De tal modo que los diferentes sistemas de integración de percepciones sensibles culminan con la creación de objetos nuevos, pero históricamente situados, que permiten a las sociedades desarrollar su propia existencia en el campo de la cultura.

Paul Valéry en "La conquista de la ubicuidad" (1928, p. 131) indica:

(...) hay en todas las artes una parte física que ya no puede ser mirada ni tratada como antes, que no puede ser mantenida al margen de las empresas del conocimiento y el poder moderno. Ni la materia, ni el espacio, ni el tiempo, son de veinte años a esta parte lo que habían siempre sido. Hay que esperar que tan grandes novedades transformen toda la técnica de las artes, influyendo con ello en la inventiva misma, y quizás llegando hasta a modificar maravillosamente la noción misma de arte.

Walter Benjamin en su célebre artículo "La obra de arte en la era de la reproductibilidad técnica" [1936] cita a Valéry y desde allí problematiza el lugar de la creatividad, la circulación y la reproducción como forma posible a través de la técnica. Pero ambos, y en los inicios del siglo pasado, ubican sin decirlo, y pese a las lecturas contrarias a esta clave, a la tecnología como un lenguaje democratizante que amplía los sentidos de entender el arte como bien público. $Y$ es en este cruce de tiempos, materialidades y conceptos donde radica la potencia del diálogo entre el arte, la tecnología, la comunicación y la política.

\section{Referencias Bibliográficas}

Benjamin, W. [1936] (1989). La obra de arte en la era de su reproductibilidad técnica. En Discursos Ininterrumpidos I. Buenos Aires: Taurus.

Benjamin, W. [1931] (1989). Pequeña historia de la fotografía. En Discursos Ininterrumpidos I. Buenos Aires: Taurus.

Bourriaud, N. (2009). Postproducción. La cultura como escenario: modos en que el arte reprograma el mundo contemporáneo. Buenos Aires: Adriana Hidalgo editora.

Brea, J. L. (2007). cultura_RAM. Mutaciones de la cultura en la era de su distribución electrónica. Barcelona: Gedisa.

Cartier, H. (1961). Apunte de cátedra. FBA-UNLP.

Cartier, H. (inédito) Conferencia. La Plata Plata: Sedici-UNLP. Recuperado: 13/07/2016.

URL: http://sedici.unlp.edu.ar/handle/10915/44759 
Ceriani, A. (s/f) Sinopsis del proyecto Speak. Recuperado (29/06/16). URL: http://www.alejandraceriani.com.ar/speak.html

Dubois, P. (2000). Máquinas de imágenes: una cuestión de línea general. En Video, Cine, Godard; Libros del Rojas. Buenos Aires: Universidad de Buenos Aires.

Gadamer, H. G. (1991). La actualidad de lo bello. El arte como juego, símbolo y fiesta. Barcelona: Paidós.

Gimpel, J. (1979). Contra el arte y los artistas. O el nacimiento de una religión. Barcelona: Gedisa.

Graw, I. (2013). ¿Cuánto vale el arte? Mercado, especulación y cultura de la celebridad. Buenos Aires: Mar Dulce.

Horkheimer, M. y Adorno, T. [1947] (1998). Dialéctica de la llustración (3era ed.). Valladolid: Editorial Trotta.

Jiménez, J. (2002). Teoría del arte. Madrid: Tecnos-Alianza.

Machado, A. (2004). Artes y Medios. Aproximaciones y distinciones, La Puerta, 1 (0). La Plata: FBA-UNLP.

Manovich, L. (2005). El lenguaje de los nuevos medios de comunicación. La imagen en la era digital. Buenos Aires: Paidós.

Martín Barbero, J. (2003). La educación desde la comunicación. Bogotá: Norma.

Martín Barbero, J. (2005). Mutaciones del arte: entre sensibilidades y tecnicidades, en Cátedra de Artes, Chile. URL: http://www.mediaciones.net/2005/01/mutaciones-delarteentre-sensibilidades-y-tecnicidades/

Martín Barbero, J. (2006). La razón técnica desafía a la razón escolar. En Narodowski, Ospina y Martínez Boom (comp.); La razón técnica desafía a la razón escolar. Buenos Aires: Noveduc.

Pagola, L. (2008). Apunte del seminario: Arte mediado por tecnologías de la Maestría en Procesos educativos mediados por tecnología - CEA - UNC. URL: http://www.ocw.unc.edu.ar/cea/arte-y-tecnologia/actividades-y-materiales/apuntes

Thompson, J. B. (1998). Los media y la modernidad. Una teoría de los medios de comunicación. Barcelona: Paidós.

Valéry, P. [1928] (1999). La conquista de la ubicuidad. En Piezas sobre arte. Madrid: Ed. Antonio Machado.

Williams, R. (1992). Tecnologías de la comunicación e instituciones sociales. En Williams, R. (editor). Historia de la comunicación (vol. 2). Barcelona: Bosch Comunicación.

Williams, R. (2011). Televisión, tecnología y forma cultural. Buenos Aires: Paidós.

\section{Páginas web consultadas}

Página web del proyecto Biopus: http://www.biopus.com.ar/

Página web del proyecto Moldeo: http://www.moldeo.org/

Página del Sedici con conferencia de Héctor Cartier http://sedici.unlp.edu.ar/handle/10915/44759 
Página web de Processing https://processing.org/

Página web de Pure Data https://puredata.info/

Página web de Arduino https://www.arduino.cc/ 